\section{Amoxycillin-clavulanate for chronic wet cough in children: cautious interpretation of study findings warranted}

We read with interest the recent paper by Marchant et al comparing amoxicillinclavunate to placebo for the treatment of chronic wet cough in children. ${ }^{1}$ The authors should be commended for attempting a randomised controlled clinical trial in this group of patients that often present paediatricians with a management dilemma. Nevertheless, we have significant concerns regarding several aspects of the study methodology, analysis and interpretation and feel that the authors have overstated their conclusions. We therefore urge caution in interpretation of the study findings.

First, the definition of chronic cough used in the study (greater than 3 weeks) contradicts the authors' previously recommended definition of 4 weeks. ${ }^{2}$ Second, for their primary outcome, the authors used improvement in 'baseline cough score' based on 'validated cough diary using the verbal category descriptive (VCD) score'. While this statement is true, the VCD score has only been validated in children aged 6 years or older and when completed by the child, ${ }^{3}$ important considering few patients older than 6 years of age were recruited. Third, cough 'resolution' was defined as a reduction of $75 \%$ in the VCD score from baseline. We question the use of a median (IQR) VCD score on a scale that contains six categories. We feel it would have been preferable to report the proportion of patients with cough resolution in each VCD score category within the two groups. In Table 1 of the manuscript, it can be seen that the baseline 75th centile VCD score in both groups was 3.0. This would indicate that children whose VCD score was greater than 0.5 at study endpoint, despite significant improvement in their symptoms, would still be classified as a failure based on the primary outcome. Fourth, given the relatively long period of time that elapsed between patient recruitment and subsequent publication, it would have been interesting to know the longterm outcomes of the children. Finally, although beyond the scope of the current study, the potential impact of prolonged antibiotic treatment in selecting out resistant organisms should not be discounted.

Despite the shortcoming to the study by Marchant $e t$ al that preclude definitive conclusions, we believe it represents a valuable contribution to the literature in this challenging area. We eagerly await the results of future, adequately powered studies with more robust study endpoints to provide the definitive evidence to determine the true role of antibiotics in children with chronic wet cough.

Patrick Stark, ${ }^{1}$ Rachel Heenan, ${ }^{1}$

Francesca Orsani, ${ }^{2}$ Kim Jachno, ${ }^{2}$ Tom G Connell ${ }^{1,3,4}$

${ }^{1}$ Department of General Medicine, Royal Children's Hospital Melbourne, Melbourne, Victoria, Australia ${ }^{2}$ Clinical Epidemiology and Biostatistics Unit, Royal 
Children's Hospital Melbourne, Melbourne, Victoria, Australia

${ }^{3}$ Department of Paediatrics, University of Melbourne,

Royal Children's Hospital Melbourne, Melbourne,

Victoria, Australia

${ }^{4}$ Murdoch Children's Research Institute, Royal

Children's Hospital Melbourne, Melbourne, Victoria,

Australia

Correspondence to Dr Tom G Connell,

Department of General Medicine, Royal Children's

Hospital Melbourne, Flemington Road, Parkville,

Melbourne, Victoria 3052, Australia;

tom.connell@rch.org.au

Contributors All authors contributed to the content of the letter and have seen and approved the final version.

Competing interests None.

Provenance and peer review Not commissioned; internally peer reviewed.

To cite Stark $P$, Heenan $R$, Orsani F, et al. Thorax 2013:68:296-297.

Received 18 October 2012

Accepted 29 November 2012

Published Online First 22 December 2012

\section{SLlinked}

- http://dx.doi.org/10.1136/thoraxjnl-2012-203059

Thorax 2013;68:296-297.

doi:10.1136/thoraxinl-2012-202885

\section{REFERENCES}

1 Marchant J, Masters IB, Champion A, et al. Randomised controlled trial of amoxycillin clavulanate in children with chronic wet cough. Thorax 2012;67:689-93.

2 Chang AB, Landau LI, Van Asperen PP, et al. Cough in children: definitions and clinical evaluation. Med $J$ Aust 2006;184:398-403.

3 Chang AB, Newman RG, Carlin JB, et al. Subjective scoring of cough in children: parent-completed vs child-completed diary cards vs an objective method. Eur Respir J 1998;11:462-6. 